\title{
CORROSION INHIBITION, ADSORPTION BEHAVIOUR AND THERMODYNAMIC PROPERTIES OF $N$-CINNAMALIDENE PALMITOHYDRAZIDE ON MILD STEEL IN HYDROCHLORIC ACID SOLUTION
}

\section{NOOR KHAIRIN MOHD*; SHOOT-KIAN YEONG*; NOR AZOWA IBRAHIM**; SITI MARIAM MOHD NOR**; CHUNG-HUNG CHAN*; SOOK-WAH TANG*; WEN-HUEI LIM* and ZAINAB IDRIS*}

\begin{abstract}
The corrosion inhibitory efficiency of $\mathrm{N}$-cinnamalidene palmitohydrazide (CPH) on mild steel in $1 \mathrm{M}$ hydrochloric acid solution was studied using Tafel polarisation, electrochemical impedance spectroscopy and scanning electron microscopy-energy dispersive X-ray spectroscopy (SEM-EDX). Tafel polarisation analysis showed that the maximum inhibition efficiency $\left(\eta_{\text {Tafel }} \%\right.$ ) approached $95 \%$ in the presence of $200 \mathrm{mg}$ litre $^{-1}$ of $\mathrm{CPH}$ at 328K. The percentage inhibition efficiency increased with increasing inhibitor concentration and temperature of the test medium. Tafel polarisation study clearly revealed that $\mathrm{CPH}$ functions as a mixed-type inhibitor with a predominant anodic control. The adsorption of CPH on mild steel surface obeyed the Langmuir's adsorption isotherm. The evaluation of the thermodynamic and activation parameters indicated that the adsorption of $\mathrm{CPH}$ on the mild steel surface took place spontaneously through both physisorption and chemisorption with Gibbs free energy of adsorption $\left(\Delta G_{a d s}^{o}\right)$ values from $-34.33 \mathrm{~kJ} \mathrm{~mol}^{-1}$ to $-41.38 \mathrm{~kJ} \mathrm{~mol}^{-1}$. Impedance spectroscopy analysis showed that corrosion of mild steel in $1 \mathrm{M}$ hydrochloric acid solution was mainly controlled by a charge transfer process and CPH formed a protective film on the metal-solution interface. The protective film was further confirmed by SEM images and the elemental analysis that measured by EDX analysis.
\end{abstract}

Keywords: corrosion inhibitor, electrochemical analysis, inhibition efficiency, protective film, mild steel.

Date received: 5 December 2018; Sent for revision: 6 December 2018; Accepted: 24 March 2019.

\section{INTRODUCTION}

Mild steel is widely applied as the constructional materials for boilers, storage tanks, building constructions, reactors as well as oil and gas pipelines. Its broad applications and never-ending uses are due to its material properties that are accepted in various applications and price that

Malaysian Palm Oil Board

6 Persiaran Institusi, Bandar Baru Bangi,

43000 Kajang, Selangor, Malaysia.

E-mail: noorkhairin@mpob.gov.my

** Department of Chemistry, Faculty of Science, Universiti Putra Malaysia, 43400 UPM Serdang,

Selangor, Malaysia. relatively cheaper than other metals (Su et al., 2016). In general, mild steel is a ferrous metal with carbon content of approximately $0.05 \%-0.25 \%$ by weight. Meanwhile, acid solutions particularly hydrochloric acid are commonly used in industrial processes such as acid pickling of iron and steel; chemical cleaning and well acidification for oil and gas exploration. In these applications, acid is applied to clean metal surface and remove impurities such as stains, inorganic contaminants, corrosion products from ferrous metals. If these processes are carried out without an appropriate protection, the metal surfaces especially mild steel tends to get corroded. Once metal is exposed to acidic environment, corrosion may take place where it involves oxidation-reduction reaction. Furthermore, this 
acid-metal interaction can also lead to subsequent diffusion of hydrogen gas continuously into metal where it may gradually weaken the mechanical strength (Diblíková et al., 2014). One of the best options of protecting the metallic surfaces against corrosion in the acidic environment is through use of corrosion inhibitors (Paul et al., 2012).

The selection of inhibitors is controlled by its economic availability, efficiency to inhibit the substrate material, safety and environmental side effects. Many types of corrosion inhibitors which include anodic, cathodic, oxygen scavenger and precipitates are extensively applied to control corrosion. However, a proportion of them particularly those containing chromate, nitrite and other heavy metals were found to be toxic and harmful to ecological system especially aquatic life. The use of these inhibitors is now being gradually restricted by various environmental regulations (Roy et al., 2014). Since the use of corrosion inhibitors is still one of the most practical techniques in combating corrosion, replacement of these inorganic inhibitors with green, non-toxic and safe chemicals is very crucial. These safety and environmental issues have encouraged people to use organic inhibitors in order to address the hazard of those toxic corrosion inhibitors. The effectiveness of organic inhibitors depends largely on the presence of heteroatoms such as sulphur, nitrogen, oxygen and/or multiple bonds (Verma and Quraishi, 2014; El-Maksoud, 2008). Previous studies reveal that several organic inhibitors include oxadiazoles (Chakravathy and Mohana, 2014), thiosemicarbazides (Ramya et al., 2015), Schiff bases (Singh and Quraishi, 2012; Ramesh and Adhikari, 2007), henna extract (Hamdy and ElGendy, 2013) and 2-mercaptothiazoline (Solmaz et al., 2008) have shown good inhibition properties on various metallic surfaces in acidic media.

Schiff base compounds are effective corrosion inhibitors for corrosion of mild steel (Verma and Quraishi, 2014; Chitra et al., 2010; Desai et al., 1986), aluminium (Safak et al., 2012), copper (Li et al., 1999), nickel (Mishra et al., 2015) and zinc (Tawfik and Zaky, 2015) in acidic media like hydrochloric acid, nitric acid, sulphuric acid and phosphoric acid. The specific interaction between functionalities in Schiff base compounds with metal surface is a crucial part for the mechanistic performance of molecules (Chitra et al., 2010). Imine group in Schiff base molecules can act as an active centres for adsorption on the metal surfaces. This is commonly followed by formation of a protective layer that protects the surface from elements causing corrosion. Molecular weight, polarity, water miscibility, electron density, boiling point and melting point are important properties to be considered for selecting effective corrosion inhibitors.
The inhibitory activities of organic molecules are accomplished not only through adsorption of active centres alone but also could be supported by the presence of long-chain alkyl group. Schiff base with long-chain alkyl can be produced from nitrogen-based compounds derived from vegetable oils such as palm oil, soyabean oil, rapeseed oil and so forth. Malaysia as one of the world's largest palm oil producers and the growth of oleochemical industry sectors offers a great opportunity to apply palm-based sources for development of downstream products particularly corrosion inhibitors (Kushairi et al., 2018; Rafiquee et al., 2007). A new Schiff base compound namely, $N$-cinnamalidene palmitohydrazide $(\mathrm{CPH})$ was synthesised from palmityl hydrazide and transcinnamaldehyde; and was applied for corrosion inhibitor. The inhibition properties of $\mathrm{CPH}$ were tested on corrosion of mild steel in acidic medium using electrochemical and surface analyses.

\section{MATERIALS AND METHOD}

\section{Preparation of $N$-cinnamalidenePalmitohydrazide}

A mixture of palmitate hydrazide, transcinnamaldehyde and dimethylformamide was charged into a two-necked reaction flask equipped with a condenser and a recirculating chiller. The reaction mixture was then heated at $90^{\circ} \mathrm{C}$ for $2 \mathrm{hr}$. After cooling to room temperature, the precipitates were filtered off under vacuum and recrystallised using dimethylformamide and water. Offwhite solid product obtained from this one-pot synthesis was collected and dried in an oven for overnight. The $\mathrm{CPH}$ obtained was characterised by infrared spectroscopy (Nicolet Magna-IR 550 Spectrometer II), Nuclear magnetic resonance (NMR) spectroscopy (JEOL JNM ECZR 600MHz), mass spectroscopy (Agilent 5975C).

\section{Electrochemical Measurement}

The electrochemical measurements were performed using a three-electrode cell assembly potentiostat (Methrom Autolab PG 204, Netherlands) equipped with a $100-\mathrm{ml}$ waterjacketed corrosion cell. Saturated silver/silver chloride $(\mathrm{Ag} / \mathrm{AgCl})$ in $3 \mathrm{M} \mathrm{KCl}$ and platinum were used as reference and counter electrodes, respectively. Mild steel specimens with an exposed area of $4.5 \mathrm{~cm}^{2}$ were used as working electrode. The experiment was carried out under a non-stirred condition and the working electrode was immersed in the test solution at open circuit potential (OCP) for $30 \mathrm{~min}$ to attain a stabilised OCP before performing measurement. 


\section{Electrode and Solutions Preparation}

Mild steel coupons of dimension $2.5 \mathrm{~cm} \times 2.5 \mathrm{~cm}$ x $0.3 \mathrm{~cm}$ (wt. \% composition: $0.32 \mathrm{Mn}, 0.09 \mathrm{Cu}, 0.07$ C, $0.04 \mathrm{Cr}, 0.03 \mathrm{~Pb}, 0.03 \mathrm{Ni}, 0.02 \mathrm{Al}$ and $0.01 \mathrm{~S}$ and the remainder is iron) were mechanically abraded with different grades of emery papers. The metal composition was measured using spark emission spectroscopy (Foundry-Master, Germany). The mild steel coupons were washed with distilled water, degreased with acetone and kept in a desiccator. This procedure was carried out prior to each experiment. The aggressive solutions of $1 \mathrm{M}$ hydrochloric acid solution were diluted from 37\% hydrochloric acid (AR grade, Merck Germany) using high-purity deionised water (resistivity $\sim 18.2$ $\mathrm{M} \Omega . \mathrm{cm}$ ) that was obtained from a laboratory water purification system (ELGA, United Kingdom). Inhibited $1 \mathrm{M}$ hydrochloric acid solutions were prepared by diluting inhibitor solution in alcohol with $1 \mathrm{M}$ hydrochloric acid solution to obtain various concentrations: 25-200 mg litre ${ }^{-1}$.

\section{Electrochemical Impedance Spectroscopy}

Electrochemical impedance spectroscopy was carried out to have a thorough understanding of the corrosion product film and inhibitor performance through electrochemical system. Impedance behaviour is commonly explained by pure electrical models that are used to verify and calculate the numerical values corresponding to the electrochemical system under examination. The measurement was performed at an open circuit potential in the frequency range from $100 \mathrm{kHz}$ to $0.01 \mathrm{~Hz}$ with amplitude of $5 \mathrm{mV}$ as excitation signal and scan rate of $1 \mathrm{mV} \mathrm{s}^{-1}$. Data obtained was fitted with sets of equivalent circuits using NOVA software. The percentages of inhibition efficiency from impedance measurements were calculated using charge transfer resistance values as expressed by Equation (1):

$$
\eta_{\mathrm{EIS}}(\%)=\frac{R_{c t}-R_{{ }^{\prime} c t}}{R_{c t}} \times 100
$$

where $R_{c t}$ and $R_{c t}^{\prime}$ are the charge transfer resistances of working electrode in the absence and presence of inhibitor, respectively.

\section{Tafel Polarisation}

The Tafel polarisation measurements were started from cathodic to the anodic reactions ( $\mathrm{E}=\mathrm{E}_{\text {corr }} \pm 250 \mathrm{mV}$, where $\mathrm{E}$ is potential and $\mathrm{E}_{\text {corr }}$ is corrosion potential) at a constant sweep rate of $1 \mathrm{mV} \mathrm{s}^{-1}$. The low sweep rate was set to obtain a steady state current-potential curve (Rivera-Grau et al., 2013). The corrosion potential $\left(\mathrm{E}_{\text {corr }}\right)$ was observed when the electrode attained a steady state. A plot of potential, E against $\log \mathrm{i}_{\text {corr }}$ (Tafel plot) was constructed and the linear Tafel segments of anodic and cathodic curves were extrapolated to obtain corrosion current density $\left(\mathrm{i}_{\text {corr }}\right)$ and $\mathrm{E}_{\text {corr }}$. The corrosion rate (CR) and percentage of inhibition efficiency $\eta_{\text {Tafel }}(\%)$ was calculated using Equations (1) and (2) (Shahin et al., 2003).

Corrosion rate, $\mathrm{CR}\left(\mathrm{mm} \mathrm{yr}^{-1}\right)=\frac{0.129 \times \mathrm{Eq} . \mathrm{W} \times \mathrm{i}_{\text {corr }}}{d}$

Inhibition efficiency, $\eta_{\text {Tafel }} \%=\frac{\left(\mathrm{i}_{\text {çorr }}^{\prime}-\mathrm{i}_{\text {corr }}\right)}{\mathrm{i}_{\text {corr }}} \times 100$

where Eq.W and $d$ are the equivalent weight (g) and density $\left(\mathrm{g} \mathrm{cm}^{-3}\right)$ of the corroding metal, respectively. The $\mathrm{i}_{\text {corr }}$ and $\mathrm{i}_{\text {corr }}$ are the corrosion current density values in blank and in the presence of inhibitors, respectively. Adsorption isotherm of $\mathrm{CPH}$ was calculated from linear polarisation measurement.

\section{Surface Analysis}

The mild steel coupons were exposed to $1 \mathrm{M}$ hydrochloric acid solution containing $\mathrm{CPH}$ inhibitor with concentration of $200 \mathrm{mg}$ litre $^{-1}$ and also blank solution for $3 \mathrm{hr}$ and 30 days before conducting surface morphological examination. After completion of immersion test, the coupons were removed from the solutions, rinsed with acetone and dried in an oven for $2 \mathrm{hr}$. The morphological analysis was performed using SEM-EDX spectrometry (JEOL JSM 6400, Japan).

\section{RESULTS AND DISCUSSION}

\section{Characterisation of the $\mathrm{CPH}$}

$\mathrm{CPH}$ was synthesised with considerably good yield and purity of greater than $95 \%$. CPH is white powder and it is soluble in dimethyl formamide, ethanol, isopropanol, dimethylsulfoxide and chloroform. The chemical data of $\mathrm{CPH}$ is shown as follows:

Off-white solid (yield: 98\%, 0.9974 g); m.p.: $110.6^{\circ} \mathrm{C}-111.3^{\circ} \mathrm{C}$; TLC (silica): $R_{f}=0.30$ (eluent: petroleum ether-ethyl acetate, $8: 2, \mathrm{v} / \mathrm{v}) ; \mathrm{v}_{\max }(\mathrm{KBr}$, $\left.\mathrm{cm}^{-1}\right) 3200(\mathrm{~N}-\mathrm{H}), 1667(\mathrm{C}=\mathrm{O}), 1627(\mathrm{C}=\mathrm{N}), 1570(\mathrm{~N}-$ $\mathrm{H}), 1667(\mathrm{C}=\mathrm{C}), 1187(\mathrm{C}-\mathrm{N}), 722(\mathrm{~N}-\mathrm{H}) ; \delta_{\mathrm{H}}(500 \mathrm{MHz}$, $\left.\mathrm{CDCl}_{3}\right) 9.75(\mathrm{~s}, 1 \mathrm{H}, \mathrm{CON} \underline{\mathrm{H}}), 7.64(\mathrm{dd}, 1 \mathrm{H}, J 5.75 \mathrm{~Hz}$, $\mathrm{NCHC} \underline{\mathrm{H}}=\mathrm{CH}), 7.46(\mathrm{~d}, 2 \mathrm{H}, J 7.20 \mathrm{~Hz}, o$-phenyl x 2), 7.34 (t, 2H, J 7.20 Hz, m-phenyl x 2), 7.30 (t, 1H, J 7.20 
$\mathrm{Hz}, p$-phenyl), 6.88 (d, 1H, J $1.8 \mathrm{~Hz}, \mathrm{NC} \underline{\mathrm{HCH}}=\mathrm{CH})$, $6.88(\mathrm{~d}, 1 \mathrm{H}, J 6.00 \mathrm{~Hz}, \mathrm{CH}=\mathrm{CHPh}), 2.67(\mathrm{t}, 2 \mathrm{H}, J 7.8$ $\left.\mathrm{Hz}, \mathrm{CH}_{2} \mathrm{CO}\right), 1.69\left(\mathrm{~m}, 2 \mathrm{H}, \mathrm{C}_{2} \mathrm{CH}_{2} \mathrm{CO}\right), 1.34(\mathrm{~m}, 24 \mathrm{H}$, $\left.\left(\mathrm{C}_{2}\right)_{12} \mathrm{CH}_{3}\right), 0.87\left(\mathrm{t}, 3 \mathrm{H}, J 7.20 \mathrm{~Hz}, \mathrm{CH}_{2} \mathrm{CH}_{3}\right) ; \delta_{\mathrm{C}}(125$ $\left.\mathrm{MHz}, \mathrm{CDCl}_{3}\right) 176.5$ (으), $145.7(\mathrm{CH} \underline{\mathrm{CH}}=\mathrm{CH}), 139.2$ $(\mathrm{NCHCH}=\underline{\mathrm{CH}}), 136.0(1 \mathrm{C}, \mathrm{N} \underline{\mathrm{CHCH}}=\underline{\mathrm{CH}}), 129.0(1 \mathrm{C}$, $\mathrm{CCH}=\mathrm{CH}), 128.9(2 \mathrm{C}$, phenyl), 127.1 (2C, phenyl), 124.9 (1C, phenyl), $32.6\left(\mathrm{CH}_{2} \mathrm{CO}\right), 32.0\left(\mathrm{CH}_{2} \mathrm{CH}_{2} \mathrm{CO}\right)$, $29.8\left(\underline{\mathrm{CH}}_{2}\right) 10,24.8\left(\underline{\mathrm{CH}}_{2} \mathrm{CH}_{2} \mathrm{CH}_{3}\right), 22.8\left(\underline{\mathrm{CH}}_{2} \mathrm{CH}_{3}\right)$, $14.2\left(\mathrm{CH}_{2} \mathrm{CH}_{3}\right) ; m / z(\mathrm{MS}) 456\left(\mathrm{M}^{+}, \mathrm{C}_{28} \mathrm{H}_{48} \mathrm{~N}_{2} \mathrm{OSi}^{+}\right)$.

\section{Electrochemical Impedance Spectroscopy}

The impedance measurements for mild steel in hydrochloric acid solution were carried out and data obtained are presented as Nyquist, phase and bode plots. A simple Randles CPE circuit consisting of solution resistance $\left(R_{s}\right)$, charge transfer resistance $\left(R_{c t}\right)$ and double layer capacitance $\left(C_{d l}\right)$ as shown in Figure $1 a$ was used in this study.

(a) Randles CPE Circuit Model

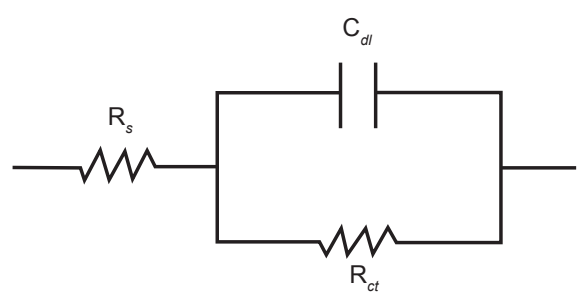

(c)

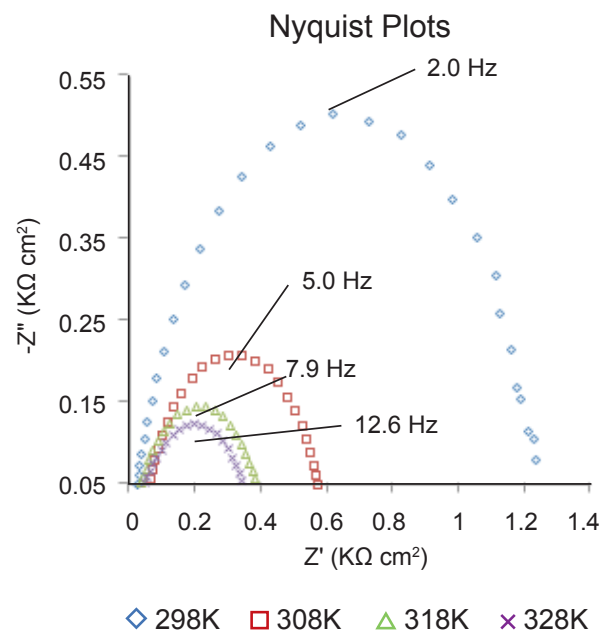

A constant phase element (CPE) was introduced instead of pure $C_{d l}$ to describe roughness and inhomogeneity of the surface which gives more accurate fit. The impedance of CPE is expressed by Equation (4). The capacitance loop intersects the real axis at higher and lower frequencies. The intersect corresponds to $R_{s}$ at high frequency and sum of $R_{s}$ and $R_{c t}$ at lower frequency. The value of $R_{c t}$ is a measure of electron transfer across the surface.

$$
Z_{C P E}=\frac{1}{Y_{o}(j \omega)^{n}}
$$

where $j=\sqrt{ }(-1), \omega$ is the angular frequency in $\operatorname{rad~s} s^{-1}, Y$ is the constant of CPE element, $n$ is an empirical constant that ranges from 0 to 1 . When $n$ $=1$, the CPE performs as a pure capacitor, if $n=0$, the CPE behaves as a pure resistor and if $n=0.5$, the CPE is an equivalent of the Warburg element.

(b)

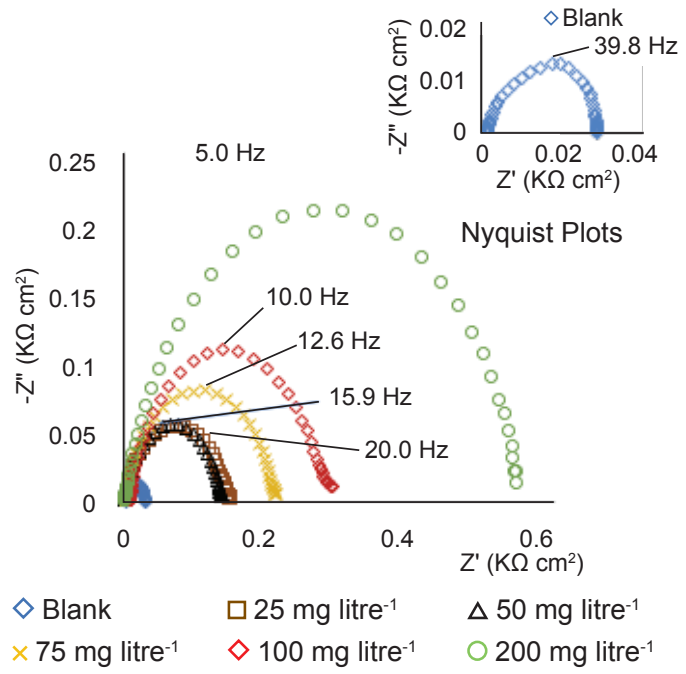

(d)
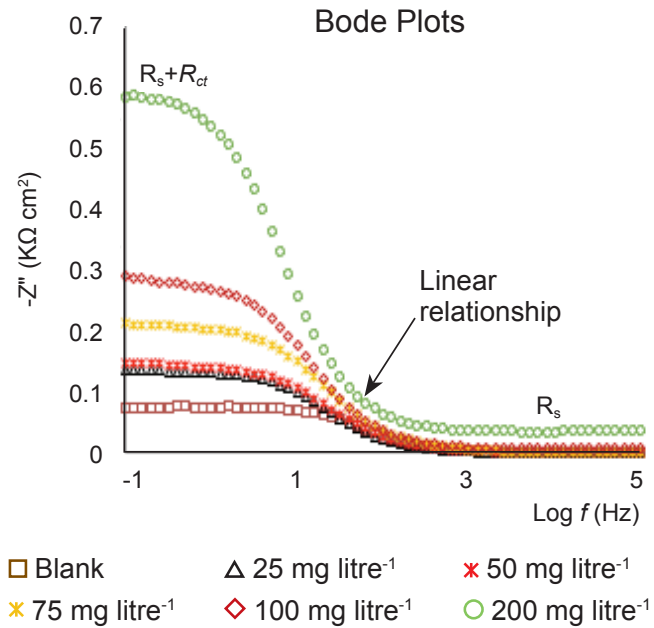

Figure 1. Randles constant phase element (CPE) Circuit Model (a) used to fit the experiment results, Nyquist plots for $\mathrm{N}$-cinnamalidene palmitohydrazide (CPH) on mild steel in $1 \mathrm{M}$ hydrochloric acid solution with concentration range from $25 \mathrm{mg} \mathrm{litre-1}$ to $200 \mathrm{mg} \mathrm{litre}^{-1}$ at $308 \mathrm{~K}$ (b), and with concentration of $200 \mathrm{mg} \mathrm{litre}^{-1}$ at 298, 308, 318 and 328K (c), and Bode plots of CPH with concentration ranged from 25 to $200 \mathrm{mg}$ litre $\mathrm{l}^{-1}$ at 308K (d). 
Warburg element is a diffusion of ohmic species at the interface. The exponent of the CPE element can be used as a gauge for the heterogeneity or roughness of the surface and $f$ is the frequency of sinusoidal perturbation signal in $\mathrm{Hz}$. The correction in the capacitance to its real value is calculated using Equation (5).

$$
C_{d l}=\frac{1}{\left(2 \pi f_{\max } R_{c t}\right)}
$$

where $f_{\max }$ is the frequency at which the imaginary component of impedance is maximum and $R_{c t}$ is obtained from the parametric fit of the experimental spectrum to the equivalent circuit equation. The $C_{d l}$ at the metal-interface is due to diffusion of soluble species.

Nyquist plots of mild steel in hydrochloric acid solution with the absence and the presence of various concentrations of $\mathrm{CPH}$ inhibitor are given in Figure 1b. It is evident from the Nyquist plots that the plots comprise of single capacitive loops. These single capacitive loops suggest that the corrosion of mild steel in $1 \mathrm{M}$ hydrochloric acid solution is mainly controlled by a charge transfer process (ElLateef, 2015). The charge transfer step dictates the rate of corrosion and the reaction is completely kinetic controlled. The shape of Nyquist plots obtained from mild steel in inhibited hydrochloric acid solutions are similar to that of blank solution indicating $\mathrm{CPH}$ inhibitor did not change the corrosion mechanism. The depressed semi-circles of Nyquist plots are often attributed to the surface roughness, inhomogeneity of the solid surface and adsorption of the inhibitor on the mild steel surface (Amin et al., 2007). It should also be noted that the peaks of the Nyquist plots are not located at the same frequencies of the apexes of the Nyquist plots.

The Nyquist plot of mild steel obtained in blank $1 \mathrm{M}$ hydrochloric acid solution exhibits the smallest capacitive loop. Then, the presence of $\mathrm{CPH}$ at 25 $\mathrm{mg}$ litre $^{-1}$ in test solution has given rise to the size of capacitive loop. This was due to formation of double layer capacitance at metal-solution interface that reduced the corroding process. Significant enlargement of the capacitive loops was observed when the inhibitor concentration was increased up to $200 \mathrm{mg}$ litre $^{-1}$. Increase of inhibitor concentration has led to significant rise of thickness of the double layer capacitance. Meanwhile, reduce in size of capacitive loops was observed when the temperature was raised fro $\mathrm{m} 298 \mathrm{~K}$ to $328 \mathrm{~K}$ (Figure 1c) with $R_{c t}$ values decreased from $1199 \Omega \mathrm{cm}^{2}$ to $308 \Omega \mathrm{cm}^{2}$ (Table 1) for mild steel in inhibited hydrochloric acid solutions. The same reduction trend was also found for mild steel in in blank solution with a similar ascending temperature. The $R_{c t}$ values decreased from $116 \Omega$ $\mathrm{cm}^{2}$ to $21 \Omega \mathrm{cm}^{2}$ as the temperature raised up to $328 \mathrm{~K}$. The smallest capacitive loop that lies on the experiment carried out at $328 \mathrm{~K}$ implies that the corrosion process accelerated at higher temperature. According to Nyquist plots and $R_{c t}$ values obtained, it can be concluded that $\mathrm{CPH}$ inhibitor has shown inhibitory action towards mild steel in hydrochloric acid solution and was still capable of reducing corrosion process even though the temperature was raised up to $328 \mathrm{~K}$.

TABLE $1 . \boldsymbol{R}_{c t}$ VALUES FOR MILD STEEL IN $1 \mathrm{M}$ HYDROCHLORIC ACID SOLUTION (blank) AND $1 \mathrm{M}$ HYDROCHLORIC ACID SOLUTION CONTAINING CPH AT DIFFERENT TEMPERATURES

\begin{tabular}{ccc}
\hline & \multicolumn{2}{c}{$\boldsymbol{R}_{c t}\left(\mathbf{\Omega} \mathbf{c m}^{2}\right)$} \\
\cline { 2 - 3 } Temperature & $\begin{array}{c}\text { 1 M hydrochloric acid } \\
\text { with presence of } \mathbf{2 0 0} \\
\text { mg litre }\end{array}$ & $\begin{array}{c}\text { 1 } \mathbf{C P H} \\
\text { M hydrochloric } \\
\text { acid without } \\
\text { inhibitor (blank) }\end{array}$ \\
\hline 298 & 1199 & 116 \\
308 & 519 & 110 \\
318 & 338 & 26 \\
328 & 308 & 21 \\
\hline
\end{tabular}

Note: $\mathrm{CPH}$ - N-cinnamalidene palmitohydrazide.

Bode plots of mild steel in $1 \mathrm{M}$ hydrochloric acid solution containing different concentrations of $\mathrm{CPH}$ inhibitor at $308 \mathrm{~K}$ are shown in Figure 1d. At low frequency, the presence of $\mathrm{CPH}$ inhibitor has enhanced the absolute impedance that confirmed the protection by inhibitor, which was attributed to the adsorption of the inhibitor molecules on the mild steel surface. A large plateau is ascribed to the corrosion of mild steel. A linear relationship between $Z^{\prime \prime}$ vs. $\log f$ that is observed at the intermediate frequencies suggesting formation of a protective film on the mild steel surface and the protective film has changed the electrode interfacial structure (ElLateef, 2015; Tan et al., 1996; Sakunthala et al., 2013). The inhibition behaviour can be explained by the structure of electrical double layer where capacitor lies between metal and the outer Helmholtz plane; and the Gouy-Chapman diffuse layer (Sigircik et al., 2016). The electrochemical impedance parameters derived from the Nyquist plots are listed in Table 2.

It is clear that the impedance response of mild steel in blank solution has tremendously changed after adding $\mathrm{CPH}$ inhibitor. The $R_{c t}$ value obtained for blank was lower than that with presence $\mathrm{CPH}$ inhibitor. Increase of $R_{c t}$ values signifies a reduction in corrosion rate due to formation of adsorbed protective film on the metal-solution interface (Bentiss et al., 2007). From the results obtained, the mild steel behaves like a pure capacitor in the hydrochloric acid solution as constant, $n$ values are very close to one. Notable decrease in $C_{d l}$ values from 57.4-48.1 $\mu \mathrm{F} \mathrm{cm}^{-2}$ was also observed with addition 
of $\mathrm{CPH}$ inhibitor. This could be attributed to the decrease in local dielectric constant $\left(\varepsilon_{\mathrm{r}}\right)$ and increase in thickness of the electrical double layer $(d)$. This phenomenon can be further understood using the Helmholtz model as shown by Equation (6).

$$
C_{d l}=\frac{A \varepsilon_{0} \varepsilon_{r}}{d}
$$

where $\varepsilon_{\mathrm{o}}$ is the permittivity of free space, $\varepsilon_{\mathrm{r}}$ is the local dielectric constant of the protective layer, $d$ is the layer thickness and $A$ is the surface area. In this model, $C_{d l}$ is inversely proportional to surface change. The replacement of water molecules (water has high dielectric constant) with relatively smaller dielectric constant of inhibitor molecules has decreased the $\varepsilon_{r}$ (Ozcan et al., 2008). On top of that, increase in thickness of the double layer at metal-solution interface has gradually reduced the $C_{d l}$ values. This provides experimental evidence of adsorption of the $\mathrm{CPH}$ molecule on the mild steel surface (Li et al., 2008). The adsorption of inhibitor also prevented the extent of the metal dissolution (Rafiquee et al., 2007). A remarkable rise of the inhibition efficiency, $\eta_{\mathrm{EIS}}(\%)$ was observed when concentration of inhibitor and temperature were increased (Figure 2). A maximum of $93.8 \%$ of inhibition efficiency was achieved for mild steel in the test solution containing $100 \mathrm{mg}$ litre $^{-1} \mathrm{CPH}$ at $328 \mathrm{~K}$.

\section{Tafel Polarisation}

Polarisation measurements were carried out to understand the inhibitive characteristic which include anodic and cathodic reactions as well as inhibition efficiency of the studied inhibitor. $\mathrm{CPH}$ inhibitor with concentration in the range of 25-200 $\mathrm{mg}$ litre $^{-1}$ in $1 \mathrm{M}$ hydrochloric acid solution was tested for corrosion inhibitory properties. Typical Tafel polarisation curves of $\log i$ against potential (Evs. $\mathrm{Ag} / \mathrm{AgCl}$ ) for mild steel in the absence and presence of different concentration of $\mathrm{CPH}$ at $308 \mathrm{~K}$ were plotted as shown in Figure 3.

It was observed that similar shape of Tafel plots were obtained for mild steel in $1 \mathrm{M}$ hydrochloric acid with the absence or presence of inhibitor indicating $\mathrm{CPH}$ inhibitor did not change the corrosion mechanism of mild steel. In the presence of inhibitor, both anodic and cathodic curves shifted to lower current densities, which reflects the inhibitory effect on both anodic and cathodic parts of polarisation curves. This indicates that $\mathrm{CPH}$ reacts as a mixedtype inhibitor (Negm et al., 2011; Bentiss et al., 2009). The shift could be attributed to the adsorption of the $\mathrm{CPH}$ inhibitor over the mild steel surface. In acidic solution, metal dissolution forms metal ions at anode and evolution of hydrogen gas from hydrogen ions occurs at the cathode. In inhibited acidic solution, $\mathrm{CPH}$ formed a barrier and reduced the corrosion rate by blocking both anodic and cathodic reactions on mild steel surface.

TABLE 2. IMPEDANCE PARAMETERS FOR CORROSION OF MILD STEEL IN 1 M HYDROCHLORIC ACID SOLUTION IN THE ABSENCE (blank) AND PRESENCE OF CPH AT 308K

\begin{tabular}{|c|c|c|c|c|c|}
\hline Sample & $\begin{array}{c}R s \\
\left(\Omega \mathrm{cm}^{2}\right)\end{array}$ & $\begin{array}{c}R_{c t} \\
\left(\Omega \mathrm{cm}^{2}\right)\end{array}$ & $n$ & $\begin{array}{c}C_{d l} \\
\left(\mu \mathrm{F} \mathrm{cm}^{-2}\right)\end{array}$ & $\begin{array}{c}\text { CPE, } Y_{o} \\
\left(\mu S \mathrm{~s} \alpha \mathrm{cm}^{-2}\right)\end{array}$ \\
\hline $1 \mathrm{M}$ hydrochloric acid without inhibitor (blank) & 1.43 & 110.3 & 0.999 & 57.4 & 69.95 \\
\hline $1 \mathrm{M}$ hydrochloric acid with $200 \mathrm{mg}$ litre $^{-1} \mathrm{CPH}$ & 3.78 & 519.0 & 0.998 & 48.1 & 61.60 \\
\hline
\end{tabular}

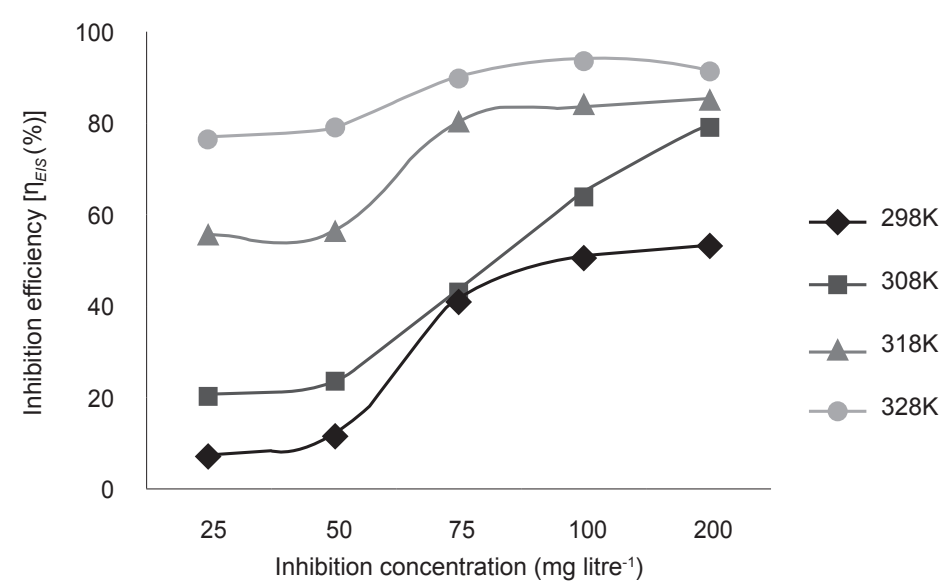

Figure 2. Inhibition efficiency, $\eta_{\mathrm{EIS}}(\%)$ of $\mathrm{N}$-cinnamalidene palmitohydrazide $(\mathrm{CPH})$ on mild steel in $1 \mathrm{M}$ hydrochloric acid solution with concentration in range of 25-200 $\mathrm{mg} \mathrm{litre}^{-1}$ at 298, 308, 318 and 328K obtained from linear polarisation analysis. 


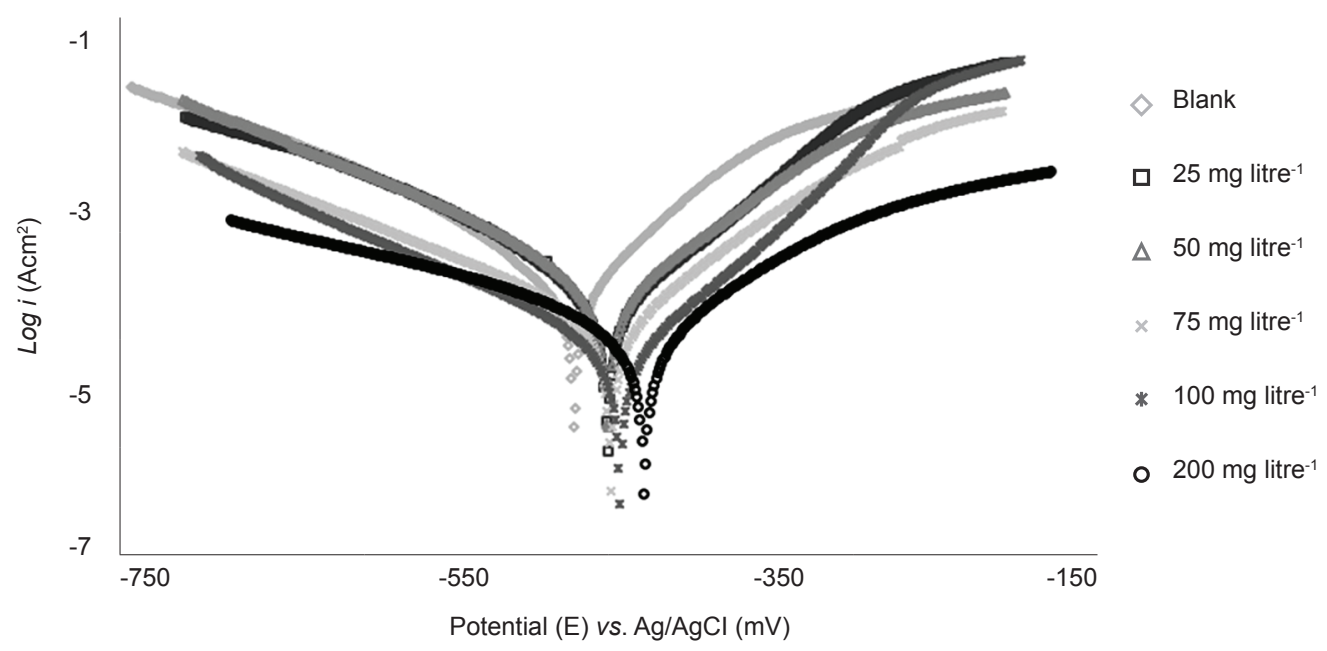

Figure 3. Tafel polarisation curves of mild steel in $1 \mathrm{M}$ hydrochloric acid solution in the absence (blank) and presence of $\mathrm{N}$-cinnamalidene palmitohydrazide (CPH) ranged from 25-200 $\mathrm{mg} \mathrm{litre}^{-1}$ at $308 \mathrm{~K}$.

TABLE 3. ELECTROCHEMICAL POLARISATION PARAMETERS FOR MILD STEEL IN 1 M HYDROCHLORIC ACID SOLUTION IN THE PRESENCE OF CPH WITH DIFFERENT CONCENTRATIONS AT 308K

\begin{tabular}{cccccc}
\hline $\begin{array}{c}\text { Concentration } \\
\left(\mathbf{m g ~ l i t r e}^{-1}\right)\end{array}$ & $\begin{array}{c}\mathbf{E}_{\text {corr }} \\
(\mathbf{m V})\end{array}$ & $\begin{array}{c}\mathbf{i}_{\text {corr }} \\
\left(\boldsymbol{\mu} \mathbf{A ~ c m} \mathbf{~ m}^{-2}\right.\end{array}$ & $\boldsymbol{\beta}_{\mathbf{a}}$ & $\boldsymbol{\beta}_{\mathbf{c}}$ & $\begin{array}{c}\mathbf{C R} \\
\mathbf{m m}_{\mathbf{~ y r}} \mathbf{r}^{-1}\end{array}$ \\
\hline Blank & -452 & 289.48 & 125.7 & 85.83 & 3.36 \\
25 & -435 & 86.39 & 99.3 & 63.2 & 1.00 \\
50 & -433 & 84.87 & 71.8 & 75.1 & 0.98 \\
75 & -430 & 83.13 & 62.7 & 66.2 & 0.97 \\
100 & -431 & 56.34 & 60.2 & 61.1 & 0.65 \\
200 & -411 & 34.59 & 44.3 & 39.0 & 0.40 \\
\hline
\end{tabular}

Note: $\mathrm{CPH}$ - $N$-cinnamalidene palmitohydrazide.

$\mathrm{CR}$ - corrossion rate.

\section{The Effect of CPH Concentration}

The increase in $\mathrm{CPH}$ inhibitor concentration has resulted in gradual shifts of both anodic and cathodic curves towards lower current densities as shown in Figure 3. The CPH inhibitor has formed a barrier that blocked the mild steel surface from both anodic and cathodic reactions. The barrier has successively reduced the surface coverage for the subsequent surface reactions and this has led to decrease of current densities (Keersmaecker et al., 2014). It is evident from Table 3 that the presence of $\mathrm{CPH}$ inhibitor has reduced $\mathrm{E}_{\text {corr }}$ value and a significant reduction of $\mathrm{E}_{\text {corr }}$ values was observed with increasing inhibitor concentrations.

Generally, the inhibitory action of an inhibitor can be classified exclusively as cathodic or anodic if the shift of $\mathrm{E}_{\text {corr }}$ with respect to $\mathrm{E}_{\text {corr }}$ of blank solution is at least $-85 \mathrm{mV}$ or $+85 \mathrm{mV}$, respectively (Li et al., 2009; Verma and Quraishi, 2014). In the present study, the maximum shift of $\mathrm{E}_{\text {corr }}$ is only $41 \mathrm{mV}$, suggesting $\mathrm{CPH}$ acts as a mixed-type inhibitor with a predominant anodic control. A closer observation also reveals a slight change in both the Tafel slopes: $\beta_{\mathrm{a}}$ and $\beta_{\mathrm{c}}$ upon addition of the inhibitor. The presence of the inhibitor has significantly influenced kinetic of metal dissolution and hydrogen evolution processes. In the absence of inhibitor, the $i_{c o r r}$ and CR values were found to be $289.48 \mu \mathrm{A} \mathrm{cm} \mathrm{cm}^{-2}$ and $3.36 \mathrm{~mm} \mathrm{yr}^{-1}$, respectively. However, the presence of $\mathrm{CPH}$ at $25 \mathrm{mg}$ litre $^{-1}$ has effectively reduced the $\mathrm{i}_{\text {corr }}$ and CR values to $86.39 \mu \mathrm{A} \mathrm{cm}-2$ and $1.00 \mathrm{~mm}$ $\mathrm{yr}^{-1}$, respectively. Further increase in the inhibitor concentrations has led to dramatic decreases of these values. The lowest values of $i_{\text {corr }}$ and $C R$ were noticed at the inhibitor solution of $200 \mathrm{mg} \mathrm{litre}^{-1}$. This may be attributed to greater surface coverage achieved at higher concentration. Remarkable increase of inhibition efficiency, $\eta_{\text {Tafel }}(\%)$ values was taking place notably with rise of the $\mathrm{CPH}$ inhibitor concentration (Figure 4). Increase in concentration allows more interaction of the inhibitor with metal surface thus improved surface coverage.

It is also seen that percentage of inhibition efficiency values calculated from both Tafel and impedance spectroscopy techniques gave similar trend upon increase concentration of inhibitor and temperature. However, values obtained from 
impedance spectroscopy were slightly lower than that of Tafel technique. A prominent increase of $\eta_{\text {Tafel }}(\%)$ values up to a maximum of $94.9 \%$ was also observed when the temperature has been risen from $298 \mathrm{~K}$ to $328 \mathrm{~K}$ (Figure 5). The greater inhibitory action achieved at $328 \mathrm{~K}$ could be associated with dispersibility of inhibitor in the test medium. As such, greater number of $\mathrm{CPH}$ molecules participated in the adsorption process.

\section{Thermodynamic Parameters}

The dependence of the CR on the temperature is expressed by the Arrhenius [Equation (7)] and Arrhenius transition state equation [Equation (8)] as follows:

Arrhenius: $\ln \mathrm{CR}=\left(\frac{-\Delta E_{a}}{R}\right)\left(\frac{1}{T}\right)+A$

Arrhenius transition state: $\ln \left(\frac{C_{R}}{T}\right)=\left[\ln \left(\frac{R}{N h}\right)+\frac{\Delta S_{a}}{R}\right]-\left(\frac{\Delta H_{a}}{R T}\right)$

where $\Delta E_{\mathrm{a}}$ is the activation energy in $\mathrm{J} \mathrm{mol}^{-1}, A$ is the electrochemical constant, $R$ is the gas constant, $T$ is the absolute temperature in Kelvin, $E_{a}$ is the activation energy, $\Delta H_{\mathrm{a}}$ is the entalphy of activation and $\Delta S_{\mathrm{a}}$ is the entrophy of activation. The graphs of In CR against 1/ T x $1000\left(\mathrm{~K}^{-1}\right)$ of mild steel of blank and inhibited $1 \mathrm{M}$ hydrochloric acid gave straight lines (Figure $5 a$ ) and $\Delta E_{\mathrm{a}}$ values were obtained from the slopes of the graphs. Meanwhile, plots of $\ln (\mathrm{CR} / \mathrm{T})$ against $1000 \times 1 / \mathrm{T}$ (Figure $5 b$ ) which also gave straight lines with slopes $\left(\Delta H_{\mathrm{a}} / \mathrm{R}\right)$ and intercepts $\left[\ln (\mathrm{R} / \mathrm{Nh})+\Delta S_{\mathrm{a}} / \mathrm{R}\right]$ were established to obtain $\Delta H_{\mathrm{a}}$ and $\Delta S_{\mathrm{a}}$ values, respectively.
TABLE 4. ACTIVATION PARAMETERS FOR THE CORROSION OF MILD STEEL IN 1 M HYDROCHLORIC ACID SOLUTION CONTAINING DIFFERENT CONCENTRATIONS OF CPH

\begin{tabular}{lcccc}
\hline Sample & $\begin{array}{c}\text { Concentration } \\
(\mathbf{m g ~ l i t r e}\end{array}$ & $\begin{array}{c}E_{\mathbf{a}} \\
\left(\mathbf{k J ~ m o l}^{-1}\right)\end{array}$ & $\begin{array}{c}\Delta \mathbf{H}_{\mathrm{a}} \\
\left(\mathbf{k J ~ m o l}^{-1}\right)\end{array}$ & $\begin{array}{c}\Delta \mathbf{S}_{\mathrm{a}} \\
\left(\mathbf{J ~ m o l}^{-1} \mathbf{K}^{-1}\right)\end{array}$ \\
\hline Blank & - & 58.51 & 55.91 & -53.94 \\
& 25 & 30.27 & 27.65 & -156.92 \\
& 50 & 24.54 & 21.94 & -174.48 \\
$\mathrm{CPH}$ & 75 & 24.38 & 21.78 & -176.58 \\
& 100 & 34.42 & 31.82 & -147.39 \\
& 200 & 31.42 & 28.82 & -160.22 \\
\hline
\end{tabular}

Note: $\mathrm{CPH}$ - N-cinnamalidene palmitohydrazide.

Data in both graphs reveals that the apparent $\Delta E_{\text {a }}$ values (Table 4) for inhibited $1 \mathrm{M}$ hydrochloric acid solutions are significantly lower than that of blank solution. This suggests that the adsorption of the $\mathrm{CPH}$ molecules on the mild steel surface predominantly occurred through chemical adsorption leading to the formation of adsorptive films (Ramya et al., 2015; Zarrouk et al., 2011). The data also reveals that the $\Delta \mathrm{H}_{\mathrm{a}}$ values for dissolution of mild steel in hydrochloric acid in the presence of $\mathrm{CPH}$ inhibitor are lower (from $21.78 \mathrm{~kJ} \mathrm{~mol}^{-1}$ to $28.82 \mathrm{~kJ} \mathrm{~mol}^{-1}$ ) than that in the absence of inhibitor $\left(55.91 \mathrm{~kJ} \mathrm{~mol}^{-1}\right)$. Values of $\Delta \mathrm{H}_{\mathrm{a}}$ are all positive which are much related to the endothermic nature of the metal dissolution process (Singh and Quraishi, 2012). Data on entropy revealed that the sign of $\Delta S_{\text {a }}$ was negative which indicates that the formation of an activated complex in the rate determining step represents an association rather than a dissociation step. A decrease in disorderliness takes place during the course of the transition from reactants to activated complex (Ramesh and Adhikari, 2007).

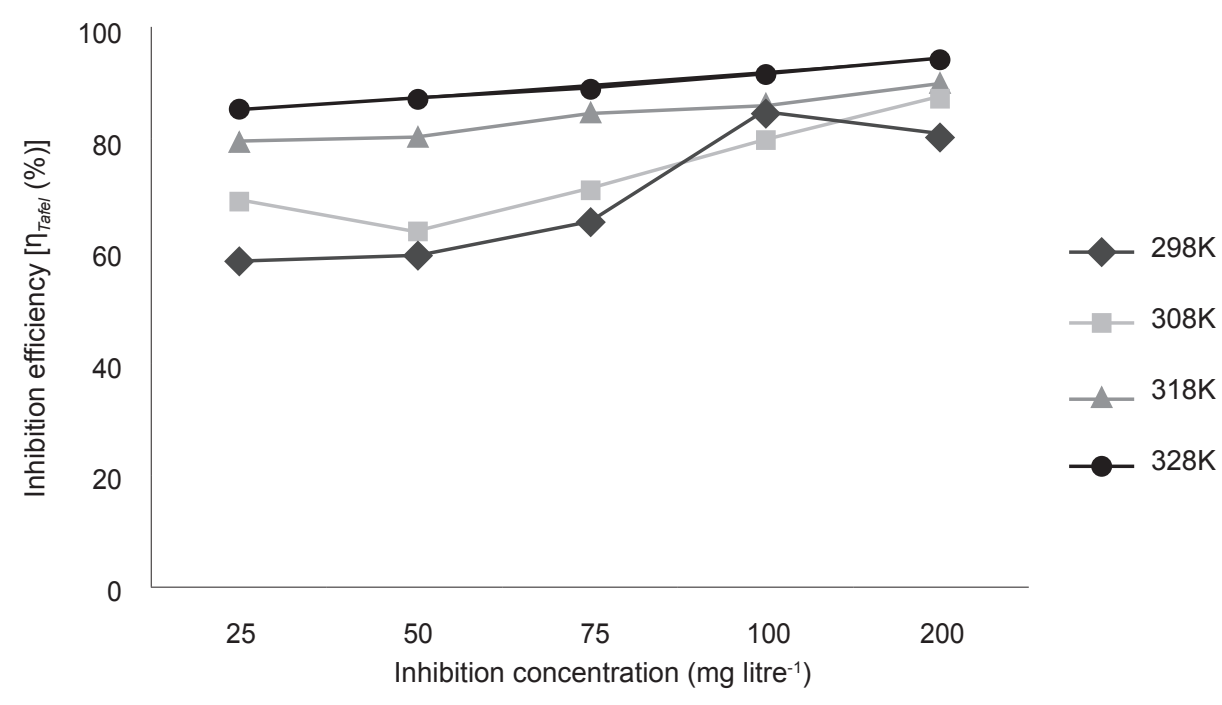

Figure 4. Inhibition efficiency, $\eta_{\text {Tafel }}(\%)$ of $\mathrm{N}$-cinnamalidene palmitohydrazide (CPH) on mild steel in $1 \mathrm{M}$ hydrochloric acid solution with different concentrations at 298, 308, 318 and 328K obtained from impedance spectroscopy analysis. 


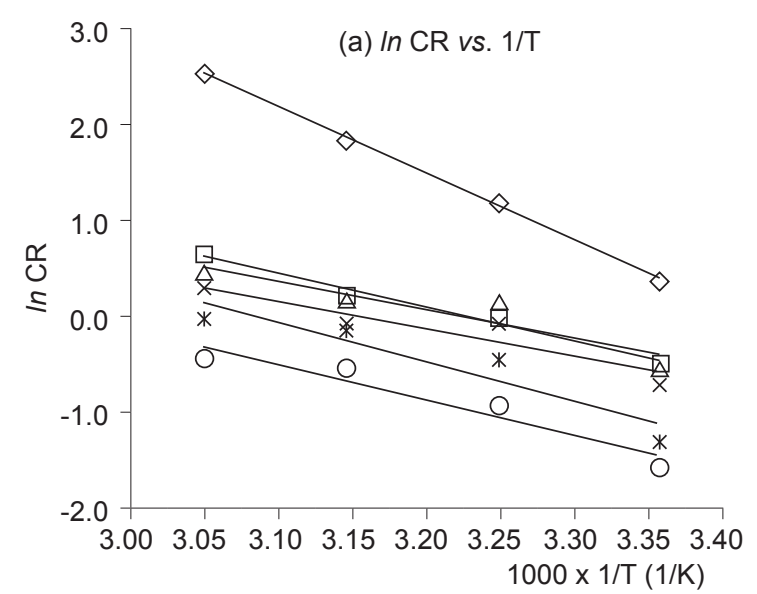

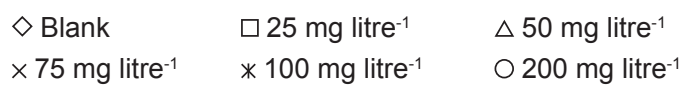

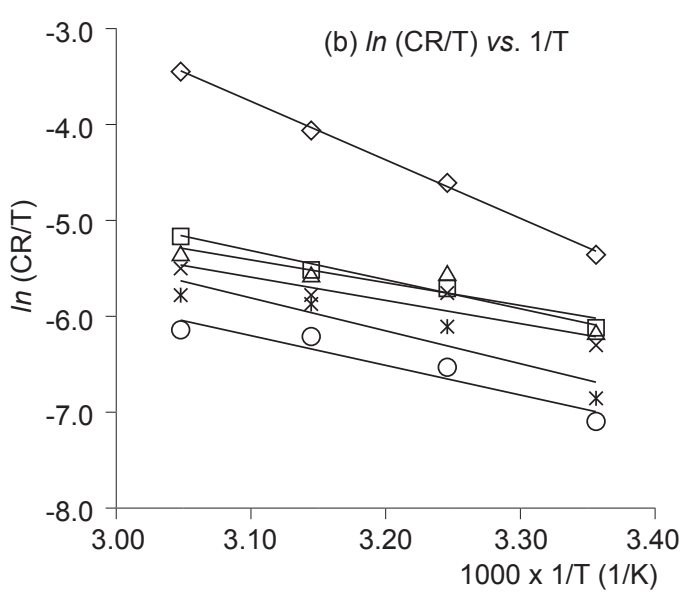

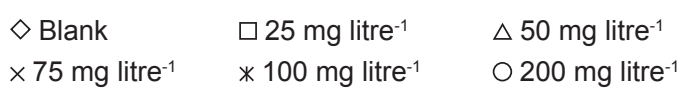

Figure 5. Plots of ln corrossion rate (CR) against 1/Tx $1000 \mathrm{~K}^{-1}$ (a) and ln CR/T against 1/Tx $1000 \mathrm{~K}^{-1}$ (b) for mild steel in $1 \mathrm{M}$ hydrochloric acid solution with the absence (blank) and presence of $200 \mathrm{mg}$ litre ${ }^{-1} \mathrm{~N}$-cinnamalidene palmitohydrazide (CPH).

\section{Adsorption Isotherm and Free Energy of Adsorption}

The mechanism of corrosion inhibition by $\mathrm{CPH}$ molecule may be explained on the basis of the adsorption behaviour. Information on the adsorption behaviour of inhibitor over metal surface can be obtained using the adsorption isotherms. Nature of testing media, chemical structure of inhibitors, charge distribution, and nature of metal primarily influence the adsorption of organic inhibitors on metal surface (Ehsani et al., 2014). Basically, the adsorption of an organic inhibitor at metal-solution interface can be presented as a substitution adsorption process between the organic molecules in aqueous solution $\mathrm{Org}_{(\mathrm{sol})}$ and the water molecules on metallic surface $\mathrm{H}_{2} \mathrm{O}_{(\mathrm{ads})}$ as shown by Equation (9).

$$
\mathrm{Org}_{\text {(sol) }}+n \mathrm{H}_{2} \mathrm{O}_{\text {(ads) }} \longleftrightarrow \operatorname{Org}_{\text {(ads) }}+n \mathrm{H}_{2} \mathrm{O}_{\text {(sol) }}
$$

where, $\mathrm{Org}_{(\mathrm{sol})}$ and $\mathrm{Org}_{(\mathrm{ads})}$ are the organic molecules in the solution and adsorbed on the metal surface, respectively and $n$ is the number of water molecules. Theoretically, the adsorption of inhibitor on corroding surfaces would not reach the real equilibrium but tends to become a quasi-equilibrium state when the rate of corrosion is sufficiently small. The quasi-equilibrium state is related to thermodynamic using appropriate equilibrium isotherms (Ghazoui et al., 2012). In this study, surface coverage $(\theta)$ values that were obtained from linear polarisation analysis were fitted with several isotherms such as Temkin, Frumkin, Langmuir and Freudlinch. The adsorption behaviour of $\mathrm{CPH}$ inhibitor on the mild steel surface is best described by the Langmuir type adsorption. The Langmuir's adsorption isotherm, $\theta$ is related to the concentration of the inhibitor as given by Equation (10).

$$
\frac{C_{i n h}}{\theta}=\frac{1}{K_{a d s}}+C_{i n h}
$$

where $C_{\text {inh }}$ is the concentration of the inhibitor, $\theta$ is the fractional surface coverage and $K_{\text {ads }}$ is the adsorption equilibrium constant obtained from the intercept of the straight line. The plots of $C_{\text {inh }} / \theta$ against $C_{\text {inh }}$ gave straight lines with linear regressions, $r^{2}$ were close to one. The $K_{\text {ads }}$ is related to the Gibbs free energy of adsorption $\left(\Delta G^{o}{ }_{\text {ads }}\right)$ as described by Equation (11).

$$
\Delta G_{\text {ads }}^{o}=-\mathrm{RT} \ln \left(55.5 K_{\mathrm{ads}}\right)
$$

where the $R$ is the universal gas constant $(\mathrm{R}=8.31446$ $\left.\mathrm{J} \mathrm{K}^{-1} \mathrm{~mol}^{-1}\right), \mathrm{T}$ is absolute temperature $(\mathrm{K})$ and the value of 55.5 represents the molar concentration of water in solution expressed in unit of mol litre ${ }^{-1}$ (El-Lateef, 2015). Table 5 shows thermodynamic parameters including $\ln K_{a d s^{\prime}} \Delta G^{o}{ }_{\text {ads }} H^{o}$ ads and $\Delta S^{o}$ ads.

It can be seen that $\ln K_{a d s}$ values increase with increasing temperature from $298 \mathrm{~K}$ to $328 \mathrm{~K}$. Such behaviour can be interpreted on the basis that increase in temperature has allowed more adsorption of CPH molecules on the metal surface. The negative values of $\Delta G^{\circ}$ ads signify a spontaneity adsorption of the $\mathrm{CPH}$ inhibitor on the mild steel surface (Solmaz 
TABLE 5. THE LANGMUIR ADSORPTION ISOTHERM AND THERMODYNAMIC PARAMETERS FOR CPH ON MILD STEEL SURFACE IN 1 M HYDROCHLORIC ACID AT DIFFERENT TEMPERATURES

\begin{tabular}{|c|c|c|c|c|c|c|}
\hline Temp. (K) & Equation & $r^{2}$ & $\begin{array}{c}\text { In } K_{a d s} \\
\left(\mathrm{~L} \mathrm{~mol}^{-1}\right)\end{array}$ & 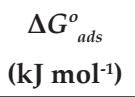 & $\begin{array}{c}\Delta H_{a d s}^{o} \\
\left(\mathrm{~kJ} \mathrm{~mol}^{-1}\right)\end{array}$ & $\begin{array}{c}\Delta S_{a d s}^{o} \\
\left(\mathrm{~J} \mathrm{~mol}^{-1} \mathrm{~K}^{-1}\right)\end{array}$ \\
\hline 298 & $y=1.1127 x+20.47$ & 0.9815 & 9.84 & -34.33 & \multirow{4}{*}{-40.47} & \multirow{4}{*}{249.8} \\
\hline 308 & $y=1.0537 x+19.11$ & 0.9908 & 9.91 & -35.66 & & \\
\hline 318 & $y=1.0724 x+6.92$ & 0.9994 & 10.92 & -39.50 & & \\
\hline 328 & $y=1.0295 x+5.49$ & 0.9994 & 11.16 & -41.38 & & \\
\hline
\end{tabular}

Note: CPH - N-cinnamalidene palmitohydrazide.

et al., 2008). Generally, values of $\Delta G_{\text {ads }}^{\text {oup }}$ up to -20

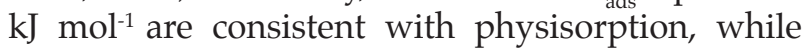
those around $-40 \mathrm{~kJ} \mathrm{~mol}^{-1}$ or higher implies strong adsorption of inhibitor molecules on the mild steel surface through co-ordinate type bond or also known as chemisorption (Solmaz et al., 2008). In the present work, the calculated values of $\Delta G^{\circ}$ ads at 298, 308, 318 and $328 \mathrm{~K}$ were $-34.33,-35.66,-39.50$ and $-41.38 \mathrm{~kJ}$ $\mathrm{mol}^{-1}$ respectively. This suggests that the adsorption of $\mathrm{CPH}$ inhibitor is not merely physisorption or chemisorption but involves both physisorption and chemisorption comprehensively. The adsorption of inhibitor accomplished with physisorption at 298K and $308 \mathrm{~K}$ but approaching chemisorption at $318 \mathrm{~K}$ and $328 \mathrm{~K}$.

Theoretically, the physisorption is an electrostatic interaction that occurs between charged molecules and charged metal surface. Chemisorption is related to charge share or charge transfer from inhibitor molecules to the mild steel surfaces (Bahrami and Hosseini, 2012). Physisorption could also take place at the initial stage of adsorption process (Solmaz et al., 2008). The enthalpy of adsorption can be calculated from Gibss-Helmholtz equation $\left(\Delta G^{o}{ }_{\text {ads }}=\Delta H^{o}{ }_{\text {ads }}-\mathrm{T} \Delta S^{o}{ }_{\text {ads }}\right)$. The adsorption process was favourable through the displacement of water molecules from the mild steel surface.

Plot of $\Delta G^{o}$ ads against $T$ gave entalphy of adsorption $\left(\Delta H^{\circ}{ }_{\text {ads }}\right)$ and the standard entropy $\left(\Delta S^{o}{ }_{\text {ads }}\right)$ according to the thermodynamic equation. The plots gave a good dependence of $\Delta G^{o}$ ads on $T$ with linear equation of $y=-0.2498 x+40.47$ and $r^{2}$ of 0.967 indicating the adsorption of inhibitors is in good correlation with thermodynamic parameters. Basically, the negative value of the entalphy of adsorption $\left(\Delta H^{o}{ }_{\text {ads }}<0\right)$ is consistent with an exothermic process that involves either physisorption or chemisorption. While the positive value $\left(\Delta H^{o}{ }_{\text {ads }}>0\right)$ is related to an endothermic process through chemisorption (Durnie et al., 2001). The positive values of $\Delta H^{o}$ ads signify a strong adsorptive activity of inhibitors onto the mild steel surface. In the present study, the negative value of $\Delta H^{o}$ ads indicates the exothermic behaviour of adsorption by $\mathrm{CPH}$ on the mild steel surface. The positive value of standard entropy $\left(\Delta S^{\circ}{ }_{\text {ads }}\right)$ suggests a random arrangement during the adsorption of inhibitor at the metal-solution interface (Benerjee and Malhotra, 1992).

\section{Surface Analysis}

SEM analysis. The SEM micrograph of the polished mild steel coupon (Figure 6a) shows a smooth surface that is free from any pit or tear. However, parallel lines on the mild steel surface are attributed to polishing scratch that are visible at micro scale. After exposing to test solution for $3 \mathrm{hr}$ (Figure 6b), the mild steel surface appeared to be moderately rough. The appearance of parallel lines indicates that the surface is free from formation of protective layer and the surface is having direct contact with corrosive solution. The surface entirely suffers from severe corrosion after exposing to test solution for 30 days. Flakes-type corrosion products found on the mild steel (Figure 6c) could be due to continuous dissolution of iron and an attack of corrosive species. Indirectly, these results also revealed that the test solution was an appropriate medium for this investigation. After exposing the mild steel coupon in the test solution containing $\mathrm{CPH}$ for $3 \mathrm{hr}$, the surface appeared to be slightly rough due to an aggressive attack of the corrosive solution (Figures $6 d$ and $6 e$ ). The disappearance of scratch lines could be correlated to the formation of the protective layer but still incomplete. A smooth surface obtained after 30 days of immersion (Figures $6 f$ and $6 g$ ) might be attributed to the adsorption of inhibitor and formation of a protective layer on the surface. Some deposited particles that were found on the mild steel surface could be due to a multiple nucleation of inhibitor on the same site (Karthikaiselvi and Subhashini, 2014). These results also revealed that $\mathrm{CPH}$ inhibited mild steel surface through formation of a protective layer.

Energy dispersive X-ray spectroscopy (EDX) analysis. The EDX analysis was conducted to determine the elements on the mild steel surface 
TABLE 6. QUANTITATIVE SEM-EDX DATA FOR POLISHED MILD STEEL AND MILD STEEL AFTER IMMERSED IN 1 M HYDROCHLORIC ACID SOLUTION IN THE ABSENCE AND THE PRESENCE OF CPH AT ROOM TEMPERATURE

\begin{tabular}{llcccc}
\hline \multirow{2}{*}{ Condition } & \multicolumn{1}{c}{ Sample } & \multicolumn{3}{c}{ Composition (\%) } \\
\cline { 3 - 6 } & & $\mathrm{C}$ & $\mathrm{Cl}$ & $\mathrm{O}$ & \multicolumn{1}{c}{ Fe } \\
\hline Before immersion & Polished mild steel & 7.47 & $\mathrm{ND}^{*}$ & $\mathrm{ND}^{*}$ & 92.15 \\
& $1 \mathrm{M} \mathrm{HCl}$ with $200 \mathrm{mg}$ litre ${ }^{-1} \mathrm{CPH}$ & 9.59 & $\mathrm{ND}^{*}$ & $\mathrm{ND}^{*}$ & 90.41 \\
\multirow{2}{*}{ After 3 hr } & $1 \mathrm{M} \mathrm{HCl}$ without inhibitor & 9.78 & $\mathrm{ND}^{*}$ & $\mathrm{ND}^{*}$ & 90.22 \\
& $1 \mathrm{M} \mathrm{HCl}$ with 200 mg litre ${ }^{-1} \mathrm{CPH}$ & 10.72 & $\mathrm{ND}^{*}$ & 7.92 & 81.04 \\
After 30 days & $1 \mathrm{M} \mathrm{HCl}$ without inhibitor & 13.09 & 10.93 & 54.31 & 19.71 \\
\hline
\end{tabular}

Note: *ND - not detected.

$\mathrm{HCl}$ - hydrochloric acid.

$\mathrm{CPH}$ - N-cinnamalidene palmitohydrazide.

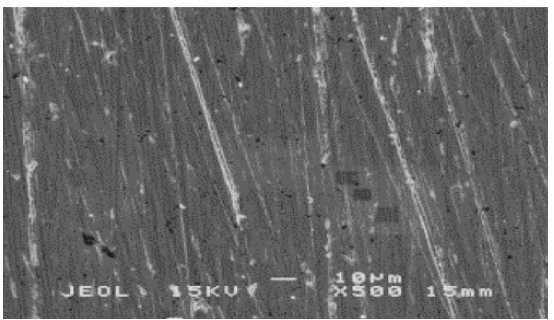

(a) Polished mild steel

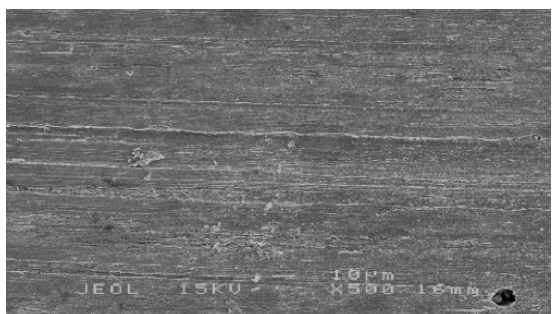

(b) Mild steel in $1 \mathrm{M} \mathrm{HCl} / 3 \mathrm{hr}$ Magnification: $500 \mathrm{X}$

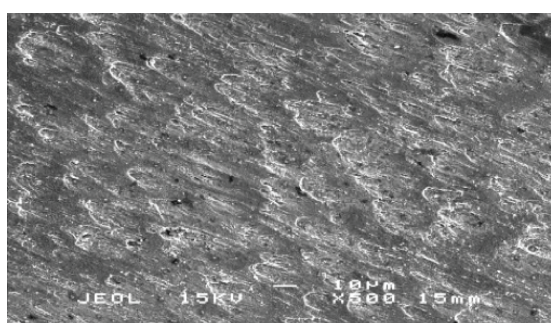

(d) Mild steel in inhibited $1 \mathrm{M} \mathrm{HCl} / 3 \mathrm{hr}$ Magnification: $500 \mathrm{X}$

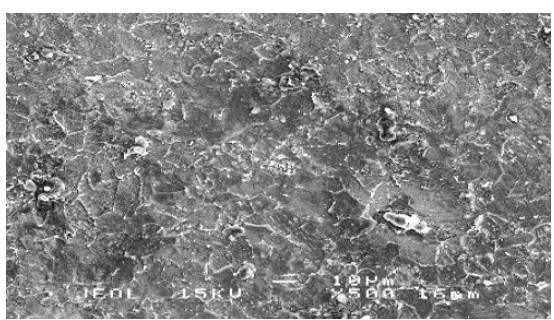

(f) Mild steel in inhibited $1 \mathrm{M} \mathrm{HCl} / 30$ days Magnification: $500 \mathrm{X}$

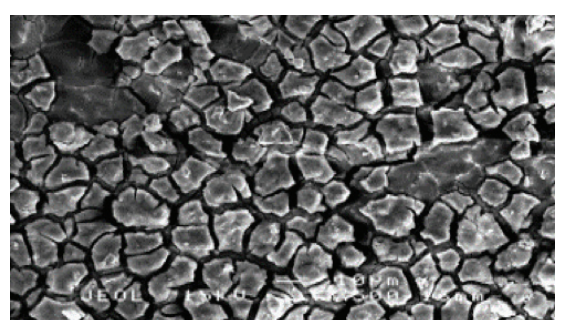

(c) Mild steel in $1 \mathrm{M} \mathrm{HCl} / 30$ days

Magnification: $500 \mathrm{X}$

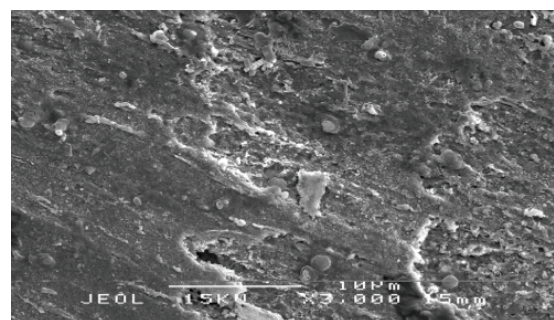

(e) Mild steel in inhibited $1 \mathrm{M} \mathrm{HCl} / 3 \mathrm{hr}$ Magnification: 3000X

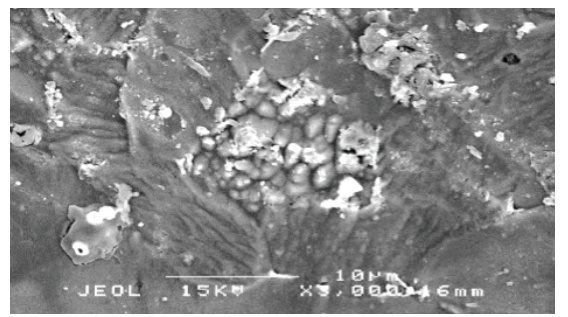

(g) Mild steel in inhibited $1 \mathrm{M} \mathrm{HCl} / 30$ days Magnification: $3000 \mathrm{X}$

Figure 6. Scanning electronic microscopy (SEM) images of a polished mild steel coupon (a), mild steel coupons after immersing in $1 \mathrm{M}$ hydrochloric acid solution for $3 \mathrm{hr}(\mathrm{b})$, and 30 days (c), mild steel coupons after exposing to $1 \mathrm{M}$ hydrochloric acid solution containing $200 \mathrm{mg}$ litre-1 CPH for $3 \mathrm{hr}$ under $500 \mathrm{X}(\mathrm{d})$ and $3000 \mathrm{X}(\mathrm{e})$ magnifications; and 30 days under $500 \mathrm{X}(\mathrm{f})$ and $3000 \mathrm{X}(\mathrm{g})$ magnifications. Images $6 a, 6 \mathrm{~b}$ and $6 \mathrm{c}$ are reproduced from Mohd et al. (2017) for comparison purpose. 
before and after immersion test. Polished mild steel coupon and mild steel coupons that were immersed in $1 \mathrm{M}$ hydrochloric acid solution with the absence (blank) and presence of $200 \mathrm{mg}$ litre-1 $\mathrm{CPH}$ for $3 \mathrm{hr}$ and 30 days are shown in Table 6.

Analysis on polished mild steel showed an absence of chlorine and oxygen particles demonstrating the surface was absolutely free from any oxide layer and/or corroded particles. Similar phenomena were also observed after $3 \mathrm{hr}$ of immersion. The absence of chlorine and oxygen atoms in this experiment could be attributed to slow corroding or adsorption processes and the formation of protective layer was still incomplete. After 30 days of exposure in the test solutions, a remarkable increase of chlorine and oxygen contents for mild steel coupons in blank solution was observed. The increase of these values could be associated with the formation of $\mathrm{FeCl}_{2^{\prime}} \mathrm{Fe}(\mathrm{OH})_{2^{\prime}}, \mathrm{Fe}_{2} \mathrm{O}_{3^{\prime}}$ and/or $\mathrm{Fe}_{3} \mathrm{O}_{4}$ resulting from the attack of $\mathrm{OH}^{-}$and $\mathrm{Cl}^{-}$ion towards $\mathrm{Fe}^{2+}$. Nevertheless, the presence of $\mathrm{CPH}$ has reduced chlorine and oxygen contents signifying possible occurrence of inhibitory activities of $\mathrm{CPH}$ on the mild steel surface. High content of Fe is commonly correlated to better inhibition behaviour. Meanwhile, mild steel severely corroded in blank solution giving very low value of Fe content.

\section{Mechanism of Inhibition}

Corrosion inhibition by $\mathrm{CPH}$ on mild steel is accomplished by adsorption of the $\mathrm{CPH}$ molecules on the mild steel surface followed by formation of a protective layer. In $1 \mathrm{M}$ hydrochloric acid solution without inhibitor, $\mathrm{Cl}^{-}$ion adsorbs on the mild steel surface to form chloro-complex at anode as follows (Yurt et al., 2004):

$$
\begin{aligned}
& \mathrm{Fe}+\mathrm{Cl}^{-} \longleftrightarrow \mathrm{FeCl}_{\text {ads }}^{-} \\
& (\mathrm{FeCl})_{\text {ads }} \longrightarrow\left(\mathrm{FeCl}_{\text {ads }}\right)_{+}+\mathrm{e} \\
& \left(\mathrm{FeCl}^{+}\right)_{\text {ads }} \longrightarrow \mathrm{Fe}^{2+}+\mathrm{Cl}^{-}
\end{aligned}
$$

Meanwhile, the cathodic hydrogen evolution follows these steps:

$$
\begin{aligned}
& \mathrm{Fe}+\mathrm{H}^{+}<\left(\mathrm{FeH}^{+}\right)_{\text {ads }} \\
& (\mathrm{FeH})_{\text {ads }}+\mathrm{e} \longrightarrow(\mathrm{FeH})_{\text {ads }} \\
& (\mathrm{FeH})_{\text {ads }}+\mathrm{H}^{+}+\mathrm{e} \longrightarrow \mathrm{Fe}+\mathrm{H}_{2}(\mathrm{~g})
\end{aligned}
$$

In inhibited $1 \mathrm{M}$ hydrochloric acid solution, $(\mathrm{FeCl})_{\text {ads }}$ form Fe-inhibitor complexes as follows:

$\left(\mathrm{FeCl}^{-}\right)_{\text {ads }}+$ Inhibitor $\longleftrightarrow$ (FeCl-Inhibitor $)_{\text {ads }}$

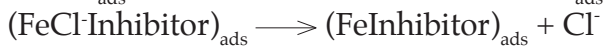

In general, two modes of adsorption could be considered. Firstly, the neutral CPH molecules may adsorb the mild steel surface on the basis of donoracceptor interactions between $\pi$-electrons and vacant $d$-orbitals of surface iron or also known as chemisorption. Furthermore, the double bonds also permit back donation of metal $d$ electrons to the $\pi^{*}$ orbital of inhibitor (Nasser and Sathiq, 2017). The unshared pair of electrons at $N$ and $\mathrm{O}$ atoms also participate in making coordinate bonds with the mild steel surface. Secondly, the inhibitor may be adsorbed through physisorption in which $\mathrm{Cl}^{-}$ions adsorb on the positively charged metal surface and create an excess of negative charges. Hence, protonated $\mathrm{CPH}$ molecules have high tendency to adsorb onto the mild steel surface thus reducing the dissolution of $\mathrm{Fe}$ to $\mathrm{Fe}^{2+}$.

\section{CONCLUSION}

$\mathrm{CPH}$ acts as appreciably good inhibitor on mild steel in $1 \mathrm{M}$ hydrochloric acid solution. Inhibition efficiencies noticeably increased with increasing inhibitor concentration and temperature. The polarisation study indicates that $\mathrm{CPH}$ function as a mixed-type corrosion inhibitor with a predominant control on anodic metal dissolution reaction. The inhibition efficiency, $\eta_{\text {Tafel }}(\%)$ calculation from Tafel analysis showed that the value approached $95 \%$ in the presence of $200 \mathrm{mg}$ litre $\mathrm{e}^{-1} \mathrm{CPH}$ at $328 \mathrm{~K}$. The adsorption of $\mathrm{CPH}$ on mild steel surface obeyed the Langmuir adsorption isotherm through both physisorption and chemisorption. SEM micrographs clearly revealed that a change in the surface characteristics of the metal surface was due to the inhibition activity by $\mathrm{CPH}$ and this finding is supported by EDX data. The inhibition efficiencies obtained from polarisation and impedance analyses are in reasonably good agreement.

\section{ACKNOWLEDGEMENT}

The authors would like to thank the DirectorGeneral of MPOB for permission to publish this article. The authors also thank Sapiah Hashim and Mohd Zambri Yusof for their technical assistance.

\section{REFERENCES}

Amin, M A; Abd El-Rehim, S S; El-Sherbini, E E F and Bayyomi, R S (2007). The inhibition of low carbon steel corrosion in hydrochloric acid solutions by succinic acid: Part I. Weight loss, polarisation, EIS, PZC, EDX and SEM studies. Electrochim. Acta, 52: 3588-3600. 
Bahrami, M J and Hosseini, S M A (2012). Electrochemical and thermodynamic investigation of the corrosion behaviour of mild steel in $1 \mathrm{M}$ $\mathrm{HCl}$ solution containing organic compounds. Int. J. Industrial Chemistry, 3: $30 \mathrm{pp}$.

Banerjee, G and Malhotra, S N (1992). Contribution to adsorption of aromatic amines on mild steel surface from $\mathrm{HCl}$ solutions by impedance, UV and raman spectroscopy. Corrosion, 48: 10-15.

Bentiss, F; Lebrini, M; Lagrenee, M; Traisnel, A; Elfarouk and Vezin, H (2007). The influence of some new 2,5-disubstituted 1,3,4-thiadiazoles on the corrosion behaviour of mild steel in $1 \mathrm{M} \mathrm{HCl}$ solution. AC impedence study and theoretical approach. Electrochim. Acta, 52: 6865-6872.

Bentiss, F; Lebrini, M; Vezin, H; Chai, F; Traisnel, $M$ and Lagrené, M (2009). Enhanced corrosion resistance of carbon steel in normal sulfuric acid medium by some macrocyclic polyether compounds containing a 1,3,4-thiadiazole moiety: AC impedance and computational studies. Corros. Sci., 51: 2165-2173.

Chakravarthy, M P and Mohana, K N (2014). Adsorption and corrosion inhibition characteristics of some nicotinamide derivatives on mild steel in hydrochloric acid solution. ISRN Corrosion. Article ID 687276.

Chitra, S; Parameswari, K and Selvaraj, A (2010). Dianiline schiff bases as inhibitors of mild steel corrosion in acid media. Int. J. Electrochem. Sci., 5: 1675-1697.

Desai, M N; Desai, M B; Shah, C B and Desai, S M (1986). Schiff bases as corrosion inhibitors for mild steel in hydrochloric acid solutions. Corros. Sci., 26: 827-837.

Diblíková, L; Jenípek, V; Hradec, P; Valeš, M and Szelag, P (2014). Mechanical and electrochemical evaluation of organic inhibitors effect on mild steel damage by hydrogen. Procedia Engineering, 74: 203308.

Durnie, W H; Kinsella, B J; De Marco, R and Jefferson, A (2001). A study of the adsorption properties of commercial carbon dioxide corrosion inhibitor formulations. J. Electrochem. Soc., 31: 1221-1226.

Ehsani, A;Mahjani, MG;Moshrefi, R; Mostaanzadeh, $\mathrm{H}$ and Shayeh, J S (2014). Electrochemical and DFT study on the inhibition of 316L stainless steel corrosion in acidic medium by 1-(4-nitrophenyl)-5amino-1H-tetrazole. RSC Adv., 4: 20031-20037.
El-Lateef, H M A (2015). Experimental and computational investigation on the corrosion inhibition characteristics of mild steel by some novel synthesised imines in hydrochloric acid solutions. Corros. Sci., 92: 104-117.

El-Maksoud, S A A (2008). The effect of organic compounds on the electrochemical behaviour of steel in acidic media. A review. Int. J. Electrochem. Sci., 3: 528-555.

Ghazoui, A; Saddik, R; Bencat, N; Hammouti, B; Guenbour, M; Zarrouk, A and Ramdani, M (2012). The role of 3-amino-2-phenylimidazo[1,2-a] pyridine as corrosion inhibitor for $\mathrm{C} 38$ steel in $1 \mathrm{M}$ HCl. Der Pharma Chem., 4: 352-364.

Hamdy, A and El-Gendy, N S (2013). Thermodynamic, adsorption and electrochemical studies for corrosion inhibition of carbon steel by henna extract in acid medium. Egypt. J. Petrol., 22: $17-25$.

Karthikaiselvi, R and Subhashini, S (2014). Study of adsorption properties and inhibition of mild steel corrosion in hydrochloric acid media by water soluble composite poly(vinyl alcohol-o-methoxy aniline). J. Assoc. Arab Univ. Basic Appl., 16: 74-82.

Keersmaecker, M D; Depla, D; Verbeken, K and Adriaens, A (2014). Electrochemical and surface study of neutralized dodecanoic acid on a lead substrate. J. Electrochem Soc., 161: C126-C137.

Kushairi, A; Loh, S K; Azman, I; Hishamuddin, E; Ong-Abdullah, M; Izuddin, Z B M N; Razmah, G; Sundram, S and Parveez, G K A (2018). Oil palm economic performance in Malaysia and R\&D progress in 2017. J. Oil Palm Res. Vol. 30(2): 163195.

Li, S; Chen, S; Lei, S; Ma, H; Yu, R and Liu, D (1999). Investigation on some Schiff bases as $\mathrm{HCl}$ corrosion inhibitors for copper. Corros. Sci., 41: 1273-1287.

Li, W H; He, Q; Zhang, S T; Pei, C L and Hou, B R (2008). Some new triazole derivatives as inhibitors for mild steel corrosion in acidic medium. J. Appl. Electrochem., 38: 289-295.

Li, X; Deng, S; Fu, H and Mu, G (2009). Inhibition effect of 6-benzylaminopurine on the corrosion of cold rolled steel in $\mathrm{H}_{2} \mathrm{SO}_{4}$ solution. Corros. Sci., 51: 620-634.

Mishra, M; Tiwari, K; Mourya, P; Singh, M M and Singh, V P (2015). Synthesis, characterisation and 
corrosion inhibition property of nickel(II) and copper(II) complexes with some acylhydrazine Schiff bases. Polyhedron, 89: 29-38.

Mohd, N K; Ghazali, M; Yeong, S K; Ibrahim, N; Yunus, W M Z W; Nor, S M M and Idris, Z (2017). Corrosion inhibition of mild steel in hydrochloric acid solution using fatty acid derivatives. J. Oil Palm Res. Vol. 29(1): 97-109.

Nasser, A J A and Sathiq, M A (2017). Comparative study of $N$-[(4-methoxyphenyl) (morpholin-4-yl) methyl]acetamide (MMPA) and N-[morpholin-4yl(phenyl)methyl]acetamide (MPA) as corrosion inhibitors for mild steel in sulfuric acid solution. Arab J. Chem., 10: S261-S273.

Negm, N A; Ghuiba, F M and Tawfik, S M (2011). Novel isoxazolium cationic Schiff base compounds as corrosion inhibitors for carbon steel in hydrochloric acid. Corros. Sci., 53: 35663575.

Özcan, M; Karadag, F and Dehri, I (2008). Investigation of adsorption characteristics of methionine at mild steel/sulfuric acid interface: An experimental and theoretical study. Colloids Surf A Physicochem Eng. Asp., 325: 57-63.

Paul, A; Joby Thomas, K; Raphael, V P and Shaju, K S (2012). 3-Formylindole-4-aminobenzoic acid: A potential corrosion inhibitor for mild steel and copper in hydrochloric acid media. ISRN Corrosion. Article ID 842836.

Rafiquee, M Z A; Saxena, N; Khan, S and Quraishi, M A (2007). Some fatty acid oxadiazoles for corrosion inhibition of mild steel in $\mathrm{HCl}$. Indian J. Chem. Technol., 14: 576-583.

Ramesh, S V and Adhikari, V (2007). Inhibition of corrosion of mild steel in acid media by N'-benzylidene-3-(quinolin-4-ylthio) propanohydrazide. Bull. Mater. Sci., 31: 699-709.

Ramya, K; Mohan, R; Anupama, K K and Joseph, A (2015). Electrochemical and theoretical studies on the synergistic interaction and corrosion inhibition of alkyl benzimidazoles and thiosemicarbazide pair on mild steel in hydrochloric acid. Mater. Chem. Phys., 149-150: 632-647.

Rivera-Grau, L M; Casales, M; Regla, I; OrtegaToledo, D M; Ascencio-Gutierrez, J A and Martinez-Gomez, L (2013). Effect of organic corrosion inhibitors on the corrosion performance of 1018 carbon steel in 3\% $\mathrm{NaCl}$ solution. Int. J. Electrochem. Sci., 8: 2491-2503.
Roy, P; Karfa, P; Adhikari, U and Sukul, D (2014). Corrosion inhibition of mild steel in acidic medium by polyacrylamide grafted Guar gum with various grafting percentage: Effect of intramolecular synergism. Corros. Sci., 88: 246-253.

Safak, S; Duran, B; Yurt, A and Türkoğlu, G (2012). Schiff bases as corrosion inhibitor for aluminium in $\mathrm{HCl}$ solution. Corros. Sci., 54: 251-259.

Sakunthala, P; Vivekananthan, S S; Gopiraman, M; Sulochana, N and Vincent, A R (2013). Spectroscopic investigations of physicochemical interactions on mild steel in an acidic medium by environmentally friendly green inhibitors. J. Surfactants Deterg., 16: 251-263.

Shahin, M; Bilgic, S and Yilmaz, H (2003). The inhibition effects of some cyclic nitrogen compounds on the corrosion of the steel in $\mathrm{NaCl}$ medium. Appl. Surf. Sci., 195: 1-7.

Sigircik, G; Tunc Tüken and Mehmet Erbil, M (2016). Assessment of the inhibition efficiency of 3,4-diaminobenzonitrile against the corrosion of steel. Corros. Sci., 102: 437-445.

Singh, A K and Quraishi, M A (2012). Study of some bidentate Schiff bases of isatin as corrosion inhibitors for mild steel in hydrochloric acid solution. Int. J. Electrochem. Sci., 7: 3222-3241.

Solmaz, R; Kardas, G; Culha, M; Yazici, B and Erbil, $M$ (2008). Investigation of adsorption and inhibitive effect of 2-mercaptothiazoline on corrosion of mild steel in hydrochloric acid media. Electrochim. Acta, 53: 5941-5952.

Su, X; Lai, C; Peng, L; Zhu, H; Zhou, L; Zhang, L; Liu, $X$ and Zhang, W (2016). A dialkyldithiophosphate derivative as mild steel corrosion inhibitor in sulfuric acid solution. Int. J. Electrochem. Sci., 11: 4828-4839.

Tan, Y J; Bailey, S and Kinsellal, B (1996). An investigation of the formation and destruction of corrosion inhibitor films using electrochemical impedance spectroscopy (EIS). Corros. Sci., 38: 15451561.

Tawfik, S M and Zaky, M F (2015). Corrosion inhibition performance of some Schiff base anionic surfactant complexes of cobalt(II), copper(II), and zinc(II) on carbon steel in $1.0 \mathrm{M} \mathrm{HCl}$. Res. Chem. Intermediat., 41: 8747-8772.

Verma, C B and Quraishi, M A (2014). Schiff's bases of glutamic acid and aldehydes as green corrosion inhibitor for mild steel: Weight-loss, electrochemical 
and surface analysis. Int. J. Innov. Res. Sci. Eng. Technol., 3: 14501-14613.

Yurt, A; Balaban, A; Ustün Kandemir, S; Bereket, G and Erk, B (2004). Investigation on some Schiff bases as $\mathrm{HCl}$ corrosion inhibitors for carbon steel. Mater. Chem. Phys., 85: 420-426.
Zarrouk, A; Hammouti, B; Zarrok, H; AlDeyab, S S and Messali, M (2011). Temperature effect, activation energies and thermodynamic adsorption studies of 1-cysteine methyl ester hydrochloride as copper corrosion inhibitor in nitric acid 2 M. Int. J. Electrochem. Sci., 6: 62616274.

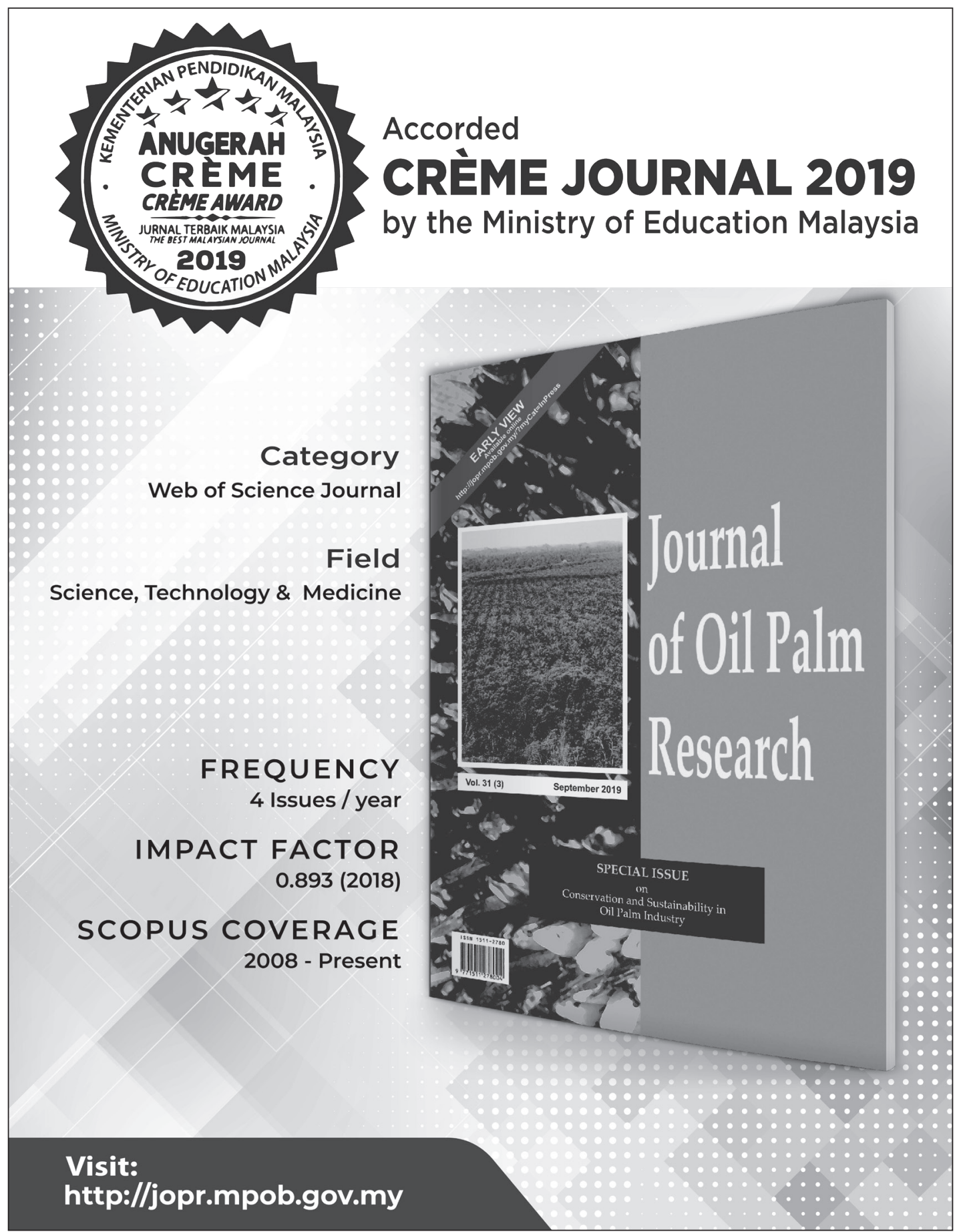

